University of Montana

ScholarWorks at University of Montana

\title{
Habitat Sampling and Habitat Selection by Female Wild Turkeys: Ecological Correlates and Reproductive Consequences
}

\author{
A. V. Badyaev \\ Thomas E. Martin \\ University of Montana - Missoula, tom.martin@umontana.edu \\ W. J. Etges
}

Follow this and additional works at: https://scholarworks.umt.edu/wildbio_pubs

Part of the Life Sciences Commons

Let us know how access to this document benefits you.

\section{Recommended Citation}

Badyaev, A. V.; Martin, Thomas E.; and Etges, W. J., "Habitat Sampling and Habitat Selection by Female Wild Turkeys: Ecological Correlates and Reproductive Consequences" (1996). Wildlife Biology Faculty Publications. 36.

https://scholarworks.umt.edu/wildbio_pubs/36

This Article is brought to you for free and open access by the Wildlife Biology at ScholarWorks at University of Montana. It has been accepted for inclusion in Wildlife Biology Faculty Publications by an authorized administrator of ScholarWorks at University of Montana. For more information, please contact scholarworks@mso.umt.edu. 


\title{
HABITAT SAMPLING AND HABITAT SELECTION BY FEMALE WILD TURKEYS: ECOLOGICAL CORRELATES AND REPRODUCTIVE CONSEQUENCES
}

\author{
AleXander V. BAdYAEV, ${ }^{1,3}$ Thomas E. MARTin, ${ }^{2}$ \\ AND WILLIAM J. ETGES ${ }^{1}$ \\ ${ }^{1}$ Arkansas Cooperative Fish and Wildlife Research Unit and Department of Biological Sciences, \\ University of Arkansas, Fayetteville, Arkansas 72701, USA; and \\ ${ }^{2}$ Montana Cooperative Wildlife Research Unit, University of Montana, Missoula, Montana 59812, USA
}

\begin{abstract}
Habitat sampling can allow much more effective habitat selection for longterm activities such as nesting and may be directly linked to fitness. We studied the process of habitat sampling and selection in female Wild Turkeys (Meleagris gallopavo) in the Arkansas Ozarks. In particular, we tested the prediction that movements prior to selecting nesting habitat correlate with the quality of selected habitat. Our results supported the prediction that greater habitat sampling (as reflected by greater area covered prior to nesting) allows acquisition of better nesting habitat; greater movements were correlated with choice of better nesting sites with more cover that allow higher nest survival. Attributes of individual birds and habitat dispersion influenced movement patterns and access to quality habitats. In addition, extent of habitat sampling early in the season correlated with reproductive performance by affecting renesting. Distance between subsequent nest locations was inversely related to the movements early in the season and also depended upon length of incubation before nest predation. Females that sampled larger areas after depredation of their first nest and did so outside of their prenesting range were more successful than other females. Received 11 August 1995, accepted 10 November 1995.
\end{abstract}

HABITAT USE can influence reproduction and survival and, thus, affect the evolution of many aspects of a species' biology (Whitham 1980, Cody 1985, Martin 1993). In particular, variation in habitat quality should favor individuals that choose habitats that yield the greatest reproductive success and survival (Fretwell and Lucas 1970, Fretwell 1972, Whitham 1980, Martin 1993). Yet, the best habitats can be limited in availability such that subordinates are prevented from settling (e.g. Jenkins et al. 1963, Brooke 1979). Covariation of habitat quality and social status suggests that organisms can assess habitat quality.

Assessments of habitat quality may improve with extent of habitat sampling (e.g. Heinrich 1979, Stephens and Krebs 1986, Orians and Wittenberger 1991, Pulliam and Danielson 1991). Habitat sampling, in turn, can be influenced by at least two factors (Fig. 1). First, it can be affected by the spatial distribution of resources relative to the mobility of the organism; the extent of resources that can be sampled should

\footnotetext{
${ }^{3}$ Present address: Division of Biological Sciences, University of Montana, Missoula, Montana 59812, USA. E-mail: abadyaev@selway.umt.edu
}

decrease with greater spatial dispersion of resources or reduced mobility of organisms. Second, attributes of individuals (e.g. physiological condition, age, social status, and prior experience) may influence the amount of time, area, and available habitats that can be searched (e.g. Parker 1983, Real 1990). Thus, effectiveness of habitat selection may be determined mechanistically by interactions among these factors (Fig. 1). Yet, the underlying correlates of individual variation in habitat sampling, and the consequences for reproduction and survival, are poorly understood.

We examined the ecological correlates of individual variation in habitat sampling and resulting habitat selection and nesting success of female Wild Turkeys (Meleagris gallopavo). In the Arkansas Ozarks, seasonal home ranges of turkeys largely overlap because there are no distinct wintering or breeding areas (Badyaev et al. 1996a). Predation during the nesting period is the most significant source of female mortality in the population, in part because incubating females are frequently attacked by predators (Badyaev unpubl. data). Thus, females might attempt to select nesting habitats that improve their safety during incubation. In our study area nest predation is unusually high 
(83\%). Evidence suggests that predation influences nest-site selection and that quality nesting habitats are limited (Badyaev 1995). In addition, Wild Turkeys are polygynous, and females choose a nesting area before they choose a mate (Healy 1992, Badyaev et al. 1996b). Thus, we assume that the amount of nesting habitat sampled is reflected by the extent of movements and amount of area covered prior to settling in a nesting habitat.

In this paper, we examine the hypothesis that females that make more extensive movements and cover larger areas before settling choose higher-quality nesting habitat (as reflected by higher nesting success). Habitat attributes associated with successful nests were identified in a companion study (Badyaev 1995). We statistically controlled for physiological condition and social status of females to address the relationship between individual competitive and physical abilities and habitat sampling. Moreover, we examined the possibility that highquality nesting habitats also included sites for renesting following a failure (Martin 1992, 1993). We tested the prediction that movements following nesting failure, but prior to renesting, were shorter for individuals that sampled more extensively prior to the initial nesting attempt because these individuals might have been more familiar with the juxtaposition of potential nesting areas. Wild Turkeys are particularly suitable for this study because: (1) individuals can differ in physiological condition at breeding (Porter et al. 1983), and physiological condition may influence habitat sampling (Fig. 1); (2) birds can easily be captured to measure body mass as an index of physiological condition; (3) birds can be monitored using radiotelemetry to examine extent and patterns of movements; and (4) habitat selection (nest sites) of first and repeat attempts can be directly identified and monitored for success relative to habitat attributes.

\section{STUdY AREA AND METHODS}

The study was conducted in the White Rock and Piney Creeks Wildlife Management Areas in the Ozark Mountains, Arkansas. Both sites are characterized by flat-topped mountains (elevation up to $746 \mathrm{~m}$ ) with numerous narrow valleys. Dominant tree species are white oak (Quercus alba), northern red oak (Q. rubra), shagbark hickory (Carya ovata), and shortleaf pine (Pinus echinata). For a detailed description of the study sites, see Badyaev (1995).

Capture sites were evenly distributed throughout

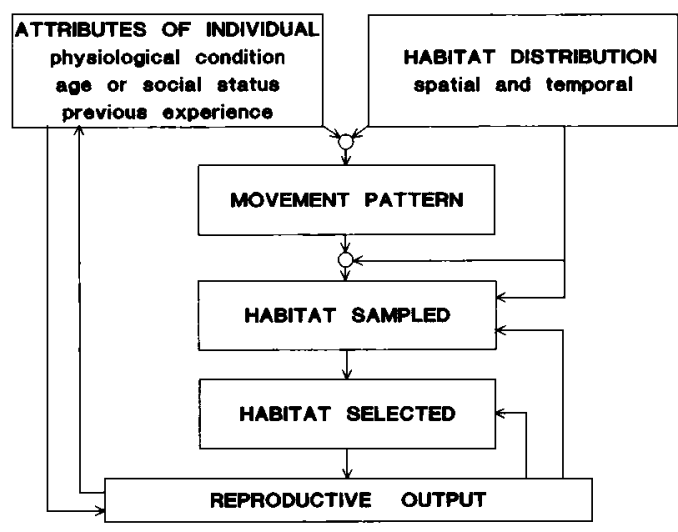

Fig. 1. Proposed interactions among habitat sampling efficiency, habitat distribution, and reproductive output.

the study area and among available cover types to ensure unbiased sampling of the population. We used cannon nets to capture 105 female turkeys in both study sites during February to March in 1992 and 1993. Females were aged following Hewitt (1967). All birds were weighed and instrumented with 120-g backpack radio transmitters. In addition, tarsus length and bill length were measured on 35 of 61 females captured during 1994. Twenty-four and 81 radiomarked females survived to the beginning of the 1992 and 1993 nesting seasons, respectively. Hens were located at different times of the day every two days from March to June (i.e. the spring dispersal and nesting periods); we obtained 4,753 locations of females during these periods. Locations were determined by plotting at least four compass bearings taken within $45 \mathrm{~min}$. Estimated distance to each radio-marked bird was $0.7 \mathrm{~km}$ or less for more than $85 \%$ of observations (for details of telemetry protocol see Badyaev et al. 1996a). We estimated spring home ranges by calculating 95\% minimum convex polygons (Kenward 1990). This method excludes from analysis the outermost $5 \%$ of locations from the arithmetic mean of all coordinates (Kenward 1990). Range overlap, estimates of home ranges, interlocation distances, and associated statistics were computed and analyzed using RANGES IV (Kenward 1990) and SAS software (SAS Institute 1989).

We distinguished several components of movement patterns (Fig. 2). First, spring dispersal was the distance between the arithmetic mean of a female's winter range (based on more than eight locations) and her first nest. Second, the prenesting range was the $95 \%$ convex polygon of the area a female covered after her initial dispersal move until the start of incubation of her first nest. Initial dispersal movement (associated with winter flock breakup) was defined as a movement greater than the mean of a female's three previous interlocation distances. For four females, 


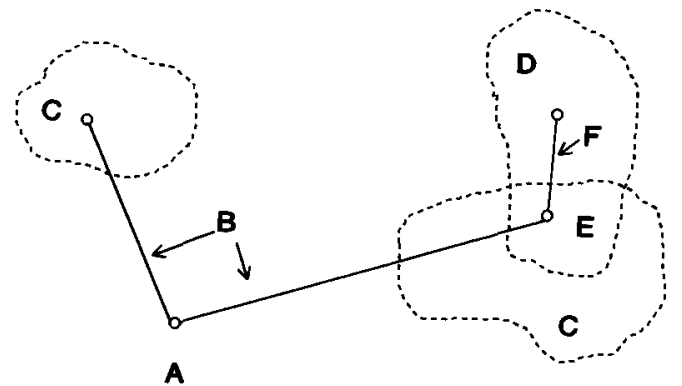

Fig. 2. Definitions of movements for two females from the same winter flock. (A) arithmetic mean of winter range; (B) spring dispersal distance; (C) prenesting range; (D) renesting range; (E) overlap between prenesting and renesting ranges; and (F) distance between first nest and renest. Many small movements occur within ranges $C$ and $D$.

prenesting ranges were calculated from 17 March until their first nest initiation, because initial dispersal move dates could not be obtained. In most cases, the initial dispersal movement was obvious, and the entire spring dispersal move was completed within two or three days. Third, distance between nests was the distance between the first nest and renest site of the same female. Fourth, renesting range was the $95 \%$ convex polygon of the area a female covered from the time her first nest failed until the start of incubation of her renest attempt.

Nest sites were marked by circling incubating hens from 40 to $50 \mathrm{~m}$ away and flagging vegetation. Only a small percentage of the nests were successful. Thus, we used the number of days each nest survived (from initiation to predation or other fate) as a relative measure of nest survival. Seven nests abandoned as a result of our disturbance were excluded from analyses. We calculated nest initiation date for most of the nests either from movement data or telemetry signal pattern (transmitters were motion-sensitive), or by subtracting the days of the egg-laying period (based on clutch size) from the first date of incubation (Schmutz and Braun 1989).

We sampled vegetation structure and composition on nest-centered and adjacent (40 $\mathrm{m}$ from the nest) plots that were $20 \mathrm{~m}$ in diameter, after nesting attempts were completed (see Badyaev 1995). We measured understory height and overstory density at the center of each plot and at four perimeter points. Litter depth and number of shrub and tree stems were measured along two perpendicular diameters within each plot. Number of stems was counted in the categories outlined by Schmutz et al. (1989) and Badyaev (1995). We used a vegetation profile board (Nudds 1977) to evaluate percentage of visual obstruction at 0.0 to 1.0 m height. The profile board was placed at the center of the plot and read from four points at the plot perimeter. It was then placed at four intermediate points
$5 \mathrm{~m}$ from the center of the plot and read from corresponding points on the plot perimeter at $10 \mathrm{~m}$ distance. Other variables measured were slope; aspect; and distance from the nest to: nearest large tree, nearest road, and nearest water source. We also measured patch size, i.e. the average radius of the most homogeneous patch of cover type around the nest (Badyaev 1995).

Most variables were transformed to improve normality (Zar 1984). Log-likelihood ratio and chi-square goodness-of-fit tests were used to evaluate differences in nesting rates and nesting success between female age classes. We used analysis of variance to test for differences in reproductive performance among age classes, years, study sites, and age-year and site-year interactions. Regression and correlation analyses were used to examine relationships among dispersal, habitat selection, and female condition parameters. We used principal components analysis to reduce the number of highly intercorrelated habitat variables and to control for multicollinearity among habitat variables in regression models (Montgomery and Peck 1992). We used the broken-stick model when constructing principal components to determine the number of interpretable eigenvalues (Jackson 1993). Sample sizes varied among tests because some data were missing. Nest initiation rate, female body mass, nest survival, and clutch sizes did not differ between years or study sites. Thus, unless otherwise indicated, data were pooled across years and study sites (Table 1).

\section{RESUlts}

\section{INDIVIDUAL ATTRIBUTES AND REPRODUCTIVE PERFORMANCE}

After-second-year females (i.e. older than two years, or ASY) did not differ from second-year females (i.e. in their second calendar year, or SY) in most reproductive parameters (Table 1). Age classes did not differ in nesting and renesting rates (all $P>0.2$ ), nesting success ( $P=$ $0.7)$, number of days nests survived ( $F=0.1$, df $=1$ and 70, $P=0.7$ ), first nest initiation date $(F$ $=0.1, \mathrm{df}=1$ and $86, P=0.7$ ), or clutch size of either first or renest attempts (both $P>0.1$ ).

Body mass of ASY females averaged 4.5 \pm SE of $0.03 \mathrm{~kg}(n=129$, range $=3.4-5.8 \mathrm{~kg})$ and was greater than that for SY females $(\bar{x}=3.6 \pm 0.05$ $\mathrm{kg}, n=40$, range $=3.0-4.4 \mathrm{~kg} ; F=39.4, \mathrm{df}=1$ and $169, P=0.001)$. Mean tarsus length of ASY females $(137.0 \mathrm{~mm}, n=14)$ also was significantly larger $(P<0.001)$ than in SY females (131.0 $\mathrm{mm}, n=14$ ), and tarsus length was highly correlated with body mass $(r=0.76, P<0.001)$. These differences in tarsus length and body mass 
between age classes suggest that age classes differ in body size rather than in physiological condition. This latter interpretation is supported by the similarities between age classes in reproductive performance (see above; Table 1).

Female body mass (partial $r_{\mathrm{p}}=0.10, P<0.01$ ) and nest initiation date $\left(r_{\mathrm{p}}=0.49, P<0.05\right)$ were the best predictors of clutch size of first nests $(P=0.001)$. Within each age class, heavier females and females that initiated nests earlier laid larger first clutches. Nests initiated earlier had better survival, with nest initiation date alone accounting for $40 \%$ of the variance in nest survival (Tables 2 and 3, Fig. 3).

\section{Habitat SAMPLING AND REPRODUCTIVE PERFORMANCE}

First nesting attempts. - Although ASY females tended to disperse shorter distances $(\bar{x}=3.81$ $\pm 0.41 \mathrm{~km}, n=56$, range $=2.94-15.78 \mathrm{~kg}$ ) from the center of their winter range to their first nest than did SY females $(\bar{x}=4.31 \pm 0.75 \mathrm{~km}$, $n=12$, range $=1.39-9.25 \mathrm{~km}$ ), the difference was not significant $(F=3.8, \mathrm{df}=1$ and $68, P=$ 0.09 ). When age was statistically controlled, heavier hens dispersed longer distances (Table 3). Females that traveled longer distances started to nest earlier, even when we controlled for body-mass effects (Table 3 ). When winter flocks disbanded, all females dispersed at the same time, regardless of age or body mass. Therefore, within flocks, individual dispersal distance was not correlated with dispersal initiation date $(P$ $>0.6)$. ASY female prenesting ranges $(\bar{x}=513.3$ \pm 77.0 ha, $n=55$, range $=13.5-3,923 \mathrm{ha}$ ) were not statistically different than those of SY females $(\bar{x}=786.5 \pm 258.3$ ha, $n=11$, range $=$ $27.2-3,011$ ha; $F=2.65$, df $=1$ and $66, P=0.14$ ). Dispersal distance was not correlated with size of prenesting range $(P>0.1)$.

Habitat of first nest sites was described by two principal components (Table 2). Prenesting range was best predicted by these two principal components and an interaction between the second principal component and female age (Table 3). Nests of females that moved over a larger area before settling (greater prenesting ranges), and those with greater visual obstruction, survived longer than nests of females that covered a smaller area and had less concealment (Table 3, Fig. 3). Thus, greater movements appeared to influence nesting success in two ways. First, females that dispersed farther nested ear-

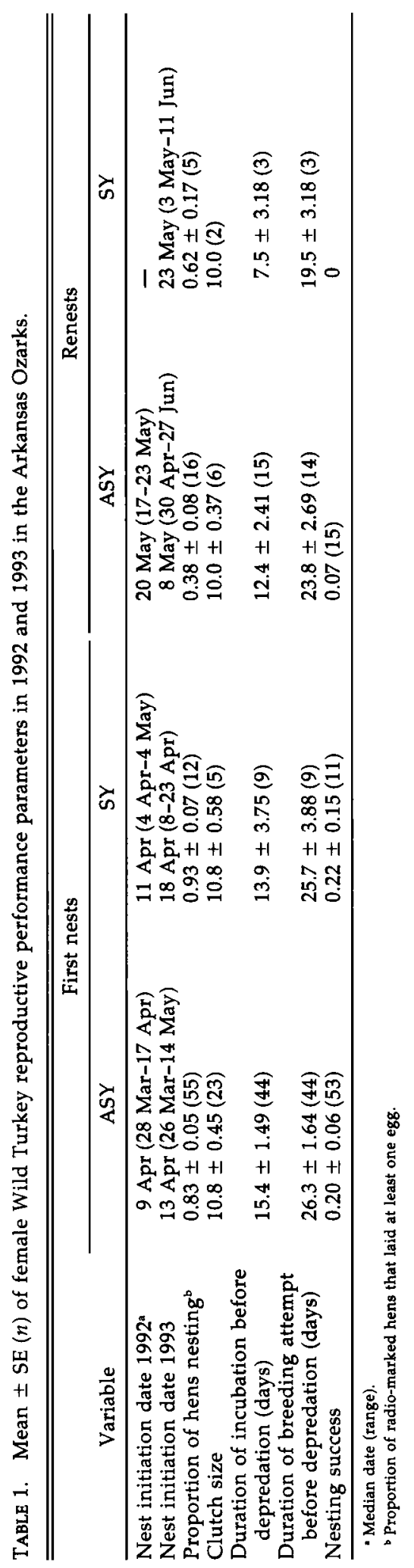


TABLE 2. Eigenvectors ${ }^{a}$ for two principal components analyses of habitat variables measured at Wild Turkey nests, and Pearson product-moment correlations of vegetation parameters at renest sites with number of days that first nest survived.

\begin{tabular}{|c|c|c|c|c|c|}
\hline \multirow[b]{2}{*}{ Variable } & \multicolumn{2}{|c|}{ First nests ${ }^{b}$} & \multicolumn{3}{|c|}{ Renests } \\
\hline & $\mathrm{PCI}$ & PCII & PCI & PCII & $r^{c}$ \\
\hline Large trees & & 0.88 & & & 0.7 \\
\hline Medium trees & & 0.50 & 0.40 & & 0.9 \\
\hline Small trees & & & 0.43 & -0.60 & \\
\hline Understory height (center) ${ }^{d}$ & & & -0.47 & 0.40 & \\
\hline Overstory density (medium) & & & 0.54 & & \\
\hline Visual obstruction (medium) & & & -0.49 & & -0.7 \\
\hline Litter depth & 0.43 & & & & \\
\hline Patch size & 0.53 & & & & 0.9 \\
\hline Slope & 0.45 & & 0.45 & & \\
\hline Distance to large tree & & & -0.48 & & \\
\hline Distance to road & & 0.51 & & & \\
\hline Explained variance (\%) & 40.0 & 19.8 & 49.7 & 25.3 & \\
\hline
\end{tabular}

- Only loadings $\geq|0.40|$ are shown.

- Only parameters that do not change over the course of nesting season are considered.

${ }^{c}$ Only coefficients significant at $P<0.05$ level are shown.

a Above nest.

- $5 \mathrm{~m}$ from nest.

lier, which allowed greater nesting success (Fig. 3). Second, greater prenesting ranges correlated with selection of nesting habitat associated with more successful nesting (Table 3, Fig. 3).

Renesting attempts. - In females that renested, clutch sizes of first nests were larger $(\bar{x}=12.11$ $\pm 0.26, n=9$, range $=11-13$ ) than clutches of renests $(\bar{x}=10.17 \pm 0.31, n=6$, range $=9-11$, paired $t$-test, $P=0.002)$. The renesting interval averaged $15.7 \pm 2.87$ days $(n=16$, range $=1-$ 45 days) for ASY females. The renesting interval was recorded for only one of five SY females that renested; this female renested 40 days after her first nest was depredated. The renesting interval increased with the number of days that first nests survived (egg laying plus incuba-

TABLE 3. Best predictors of prenesting movements and first-nest survival. $R^{2}$ is multiple coefficient of determination; $F$ is variance ratio of multiple regression; $b_{i}$ is parameter estimate; and $t$-value is for $\mathrm{H}_{\mathrm{o}}$ that parameter is equal to zero.

\begin{tabular}{|c|c|c|c|}
\hline Predictor variables & Age & $b_{i} \pm \mathrm{SE}$ & $t$ \\
\hline \multicolumn{4}{|c|}{ Dispersal distance $\left(R^{2}=0.39, F=6.30^{* * *}\right)$} \\
\hline $\begin{array}{l}\text { Female mass } \\
\text { First-nest initiation day } \times \text { age } \\
\text { Intercept }\end{array}$ & $\begin{array}{l}\text { ASY } \\
\text { SY }\end{array}$ & $\begin{array}{r}0.14 \pm 0.07 \\
-2.36 \pm 0.77 \\
-2.25 \pm 0.77 \\
7.61 \pm 1.65\end{array}$ & $\begin{aligned} & 2.87^{*} \\
- & 3.08^{* *} \\
- & 2.91^{* *} \\
& 4.60^{* * *}\end{aligned}$ \\
\hline \multicolumn{4}{|c|}{ Prenesting range $\left(R^{2}=0.65, F=11.12^{* * *}\right)$} \\
\hline Age & $\begin{array}{l}\text { ASY } \\
\text { SY }\end{array}$ & $\begin{array}{l}3.26 \pm 0.32 \\
2.99 \pm 0.36\end{array}$ & $\begin{array}{r}10.14^{* * *} \\
8.17^{* * *}\end{array}$ \\
\hline $\begin{array}{l}\text { PCI } \\
\text { PCII }\end{array}$ & & $\begin{array}{l}-0.01 \pm 0.03 \\
-0.38+0.09\end{array}$ & $\begin{array}{l}-3.15^{* *} \\
-4.29^{* * *}\end{array}$ \\
\hline PCII $\times$ age & $\begin{array}{l}\text { ASY } \\
\text { SY }\end{array}$ & $0.25 \pm 0.09$ & $2.46^{*}$ \\
\hline Intercept & & $2.18 \pm 0.12$ & $17.77^{* *}$ \\
\hline \multicolumn{4}{|c|}{ First-nest survival $\left(\boldsymbol{R}^{2}=0.67, F=8.07^{* * *}\right)$} \\
\hline $\begin{array}{l}\text { Prenesting range } \\
\text { Nest initiation date } \\
\text { Visual obstruction } \\
\text { Intercept }\end{array}$ & & $\begin{array}{r}0.11 \pm 0.05 \\
-1.82 \pm 0.40 \\
0.44 \pm 0.19 \\
3.13 \pm 0.75\end{array}$ & $\begin{array}{l}2.13^{*} \\
-4.52^{* * *} \\
2.40^{*} \\
4.16^{* * *}\end{array}$ \\
\hline
\end{tabular}

*,P<0.05; **,P<0.01; **,P<0.002.

No parameter estimate obtained. 

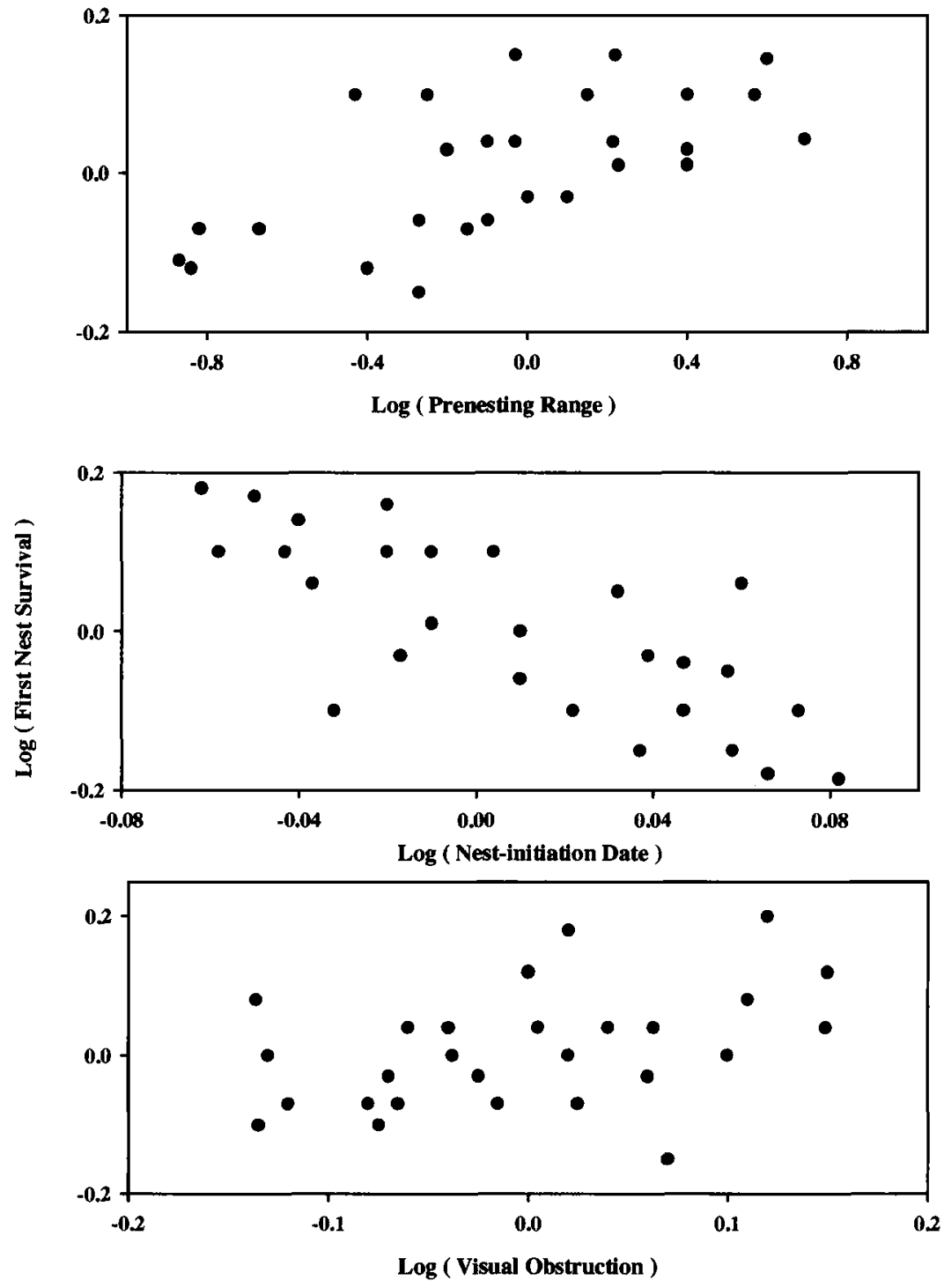

Fig. 3. Partial-regression residual plots illustrating relationship between first-nest survival and size of prenesting range, nest initiation date, and visual obstruction at nest.

tion), which accounted for $67 \%$ of the variance in renesting interval (Table 4, Fig. 4A). Renesting interval also was positively correlated with size of first clutches $\left(R^{2}=0.62, P>0.05\right.$; Fig. $4 \mathrm{~B})$ but did not enter into the model, probably because of small sample sizes. Distance between first nests and renests did not differ between ages, averaging $2.05 \pm 0.66 \mathrm{~km}(n=16$, range $=0.39-11.53 \mathrm{~km}$ ) for ASY females and $8.47 \pm$ $5.09 \mathrm{~km}(n=4$, range $=0.86-22.62 \mathrm{~km})$ for $S Y$ females $(F=0.48, \mathrm{df}=1$ and $20, P=0.49$ ). Females with greater spring dispersal distances moved shorter distances between nesting attempts. Females whose nests were depredated shortly after initiation moved farther between nesting attempts (Table 4, Fig. 5). These two parameters accounted for $84 \%$ of the variance in the distance that females moved between nesting attempts (Table 4, Fig. 5).

Renesting range averaged $237.8 \pm 52.6$ ha ( $n$ $=15$, range $=1.9-795.5$ ha) for ASY females and 69.7 ha (44.4 and 94.9 ha) for two SY females. Overlap between renesting and prenesting ranges averaged $38.5 \pm 9.41 \%$ for ASY females 
TABLE 4. Best predictors of renesting movements and survival of renesting attempt. $R^{2}$ is multiple coefficient of determination; $F$ is variance ratio of multiple regression; $b_{i}$ is parameter estimate; and $t$-value is for $H_{0}$ that parameter is equal to zero.

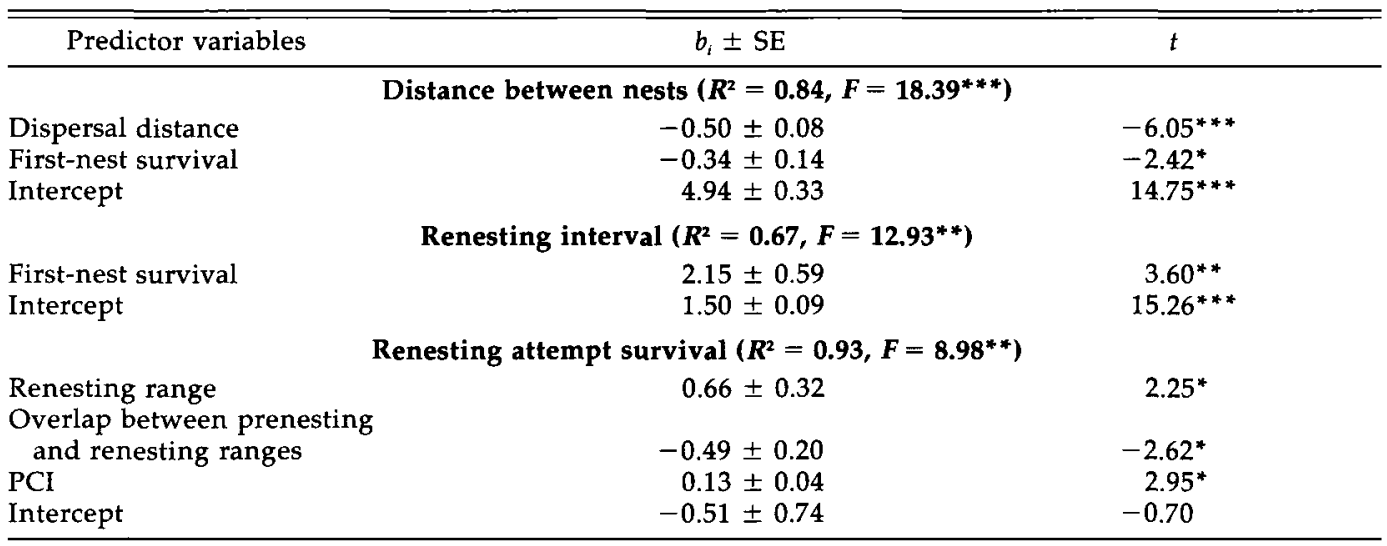

${ }^{*}, P<0.05 ;{ }^{* *}, P<0.01 ;{ }^{* *}, P<0.001$.

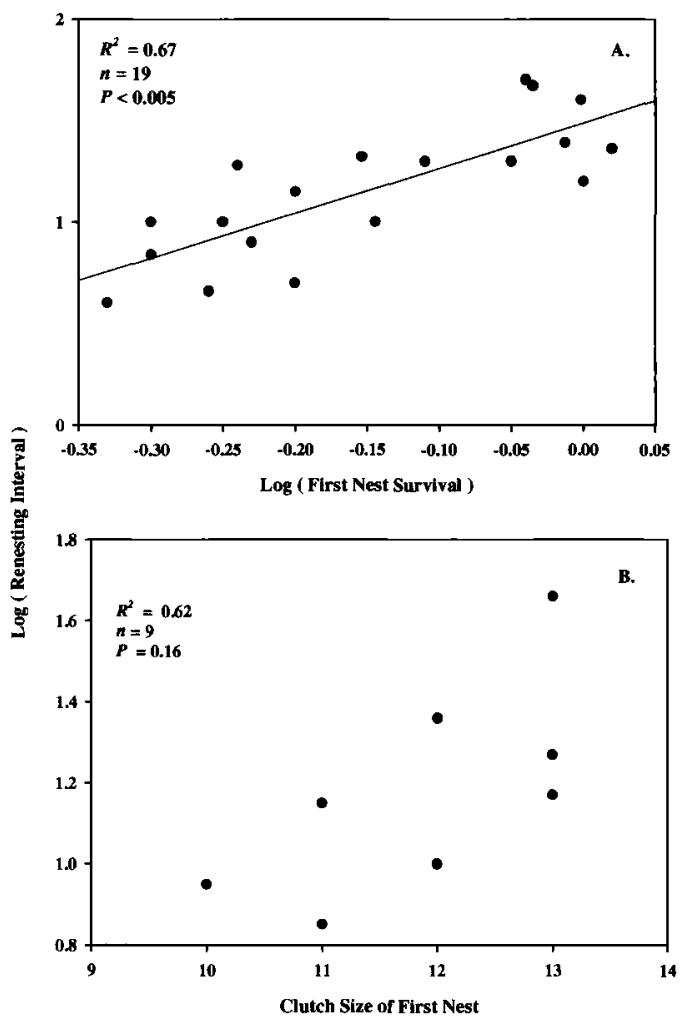

Fig. 4. (A) Linear regression of renesting interval (days) vs. first-nest incubation duration before depredation (days) and (B) relationship between first-nest clutch size and renesting interval (days). $(n=14$, range $=0-100)$ and $2.95 \%$ (1.20 and $4.70 \%$ ) for the two SY females. Overlap between prenesting and renesting ranges was not correlated with size of prenesting range, size of renesting range, or renesting interval.

Habitat of renest sites was described by two principal components (Table 2). Principal Component I, degree of overlap between prenesting and renesting ranges, and area the female covered between two consecutive nesting attempts were the best predictors of the survival probability of second nesting attempts and accounted for $93 \%$ of its variance (Table 4). Females whose first nests were depredated shortly after onset of incubation selected second nest sites with fewer medium and large trees and more understory cover than females whose nests survived longer before predation of their first nesting attempt (Table 2).

\section{Discussion}

Resource sampling can allow much more effective patch choice by foraging organisms when patch quality varies in time and space (e.g. Heinrich 1979, Parker 1983, Stephens and Krebs 1986, Real 1990). The influence of habitat sampling on effectiveness of habitat selection for activities such as nesting that may be more directly linked to fitness have been unstudied. Our results supported our prediction that greater habitat sampling, as indicated by greater movements prior to nesting, allowed selection 


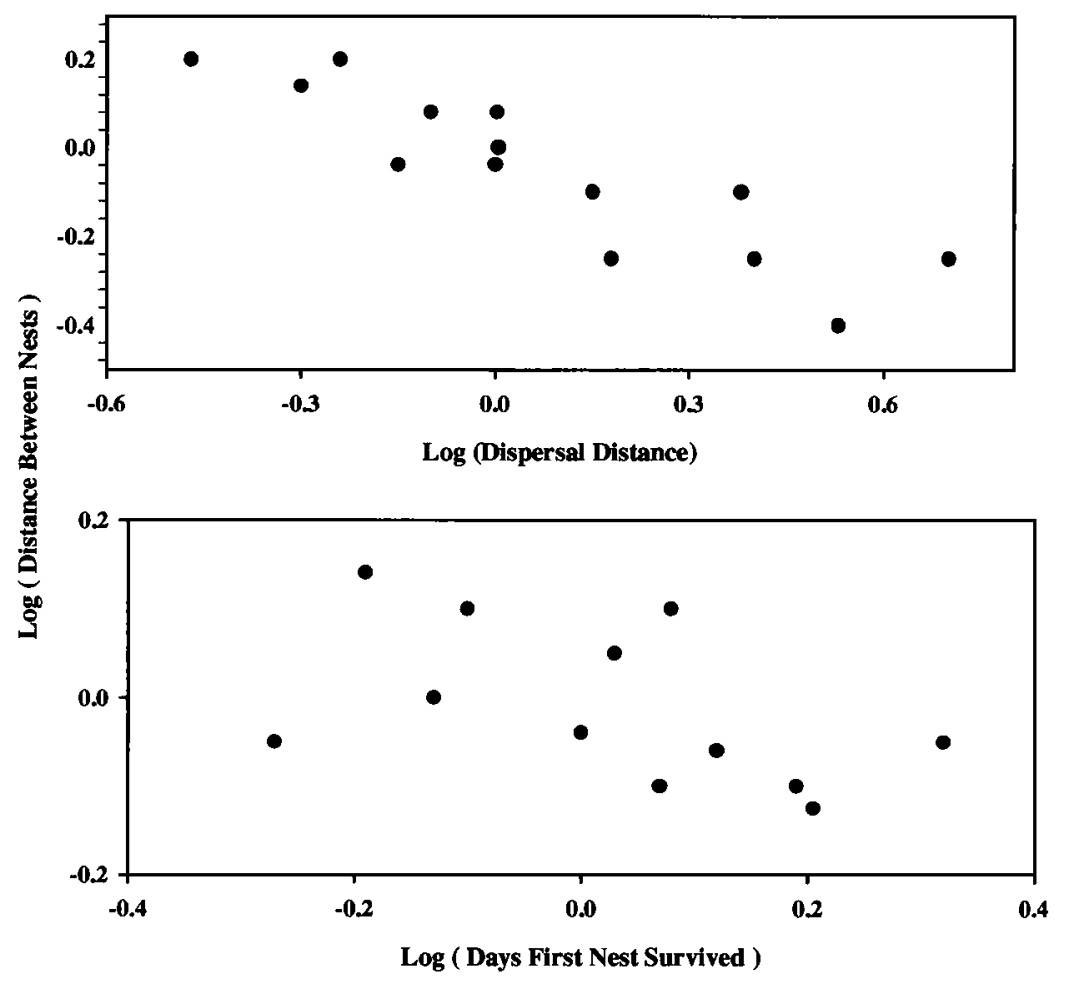

Fig. 5. Partial-regression residual plots illustrating relationship between distance from first nest and renest attempt and spring dispersal distance and number of days first nest survived.

of better nesting habitat; wider movements were correlated with choice of better nesting sites that had more cover and higher nest survival (Table 3, Fig. 3).

As predicted, attributes of individuals, such as physiological condition and social status, also were associated with habitat sampling because these parameters were correlated with spring dispersal distance. Spring dispersal distance varied with social status (here defined by age; Tables 3 and 4); ASY females tended to disperse shorter distances to the areas they subsequently searched for good nesting cover than did SY females (e.g. Schmutz and Braun 1989, Smith et al. 1989). Longer dispersal of subdominant individuals may occur because they potentially have better chances of breeding outside of areas occupied by dominant birds (e.g. Jenkins et al. 1963, Harvey et al. 1984) and greater avoidance of inbreeding and competition with siblings (see Johnson and Gaines 1990). Suitable nest sites are limited in the study area (Badyaev 1995); territorial behavior of dominant females could reduce nesting density within preferred habi- tat, as has been documented for forest grouse species (Jenkins et al. 1963, Boag et al. 1979, Zwickel 1980, Hannon et al. 1982, Nugent and Boag 1982).

The decreasing probability of nest success as the season progresses and high competition for suitable nest habitat favor early termination of spring dispersal and initiation of nest-site searching behavior (Orians and Wittenberger 1991). In this study, nests initiated earlier had a higher probability of survival than did later nests (see also Schmutz et al. 1989). Given the advantage of greater habitat sampling, as indicated by our results, selection should favor extended sampling by individuals, but extent of sampling may be limited by physiological condition. Studies of passerines suggest that individuals can differ strongly in their quality and subsequent reproductive performance, which may be related to variation in physiological condition (e.g. Högstedt 1980, Pettifor et al. 1988, Gustafsson 1989). Studies of Wild Turkeys in Minnesota indicated that individuals varied in their physiological condition due to winter ef- 


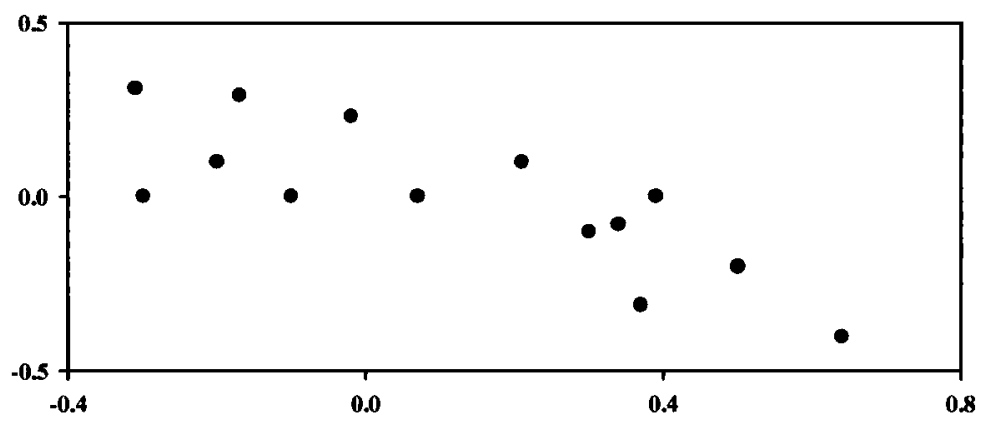

Arcsin (Percent Overlap Renesting range and Prenesting Range )
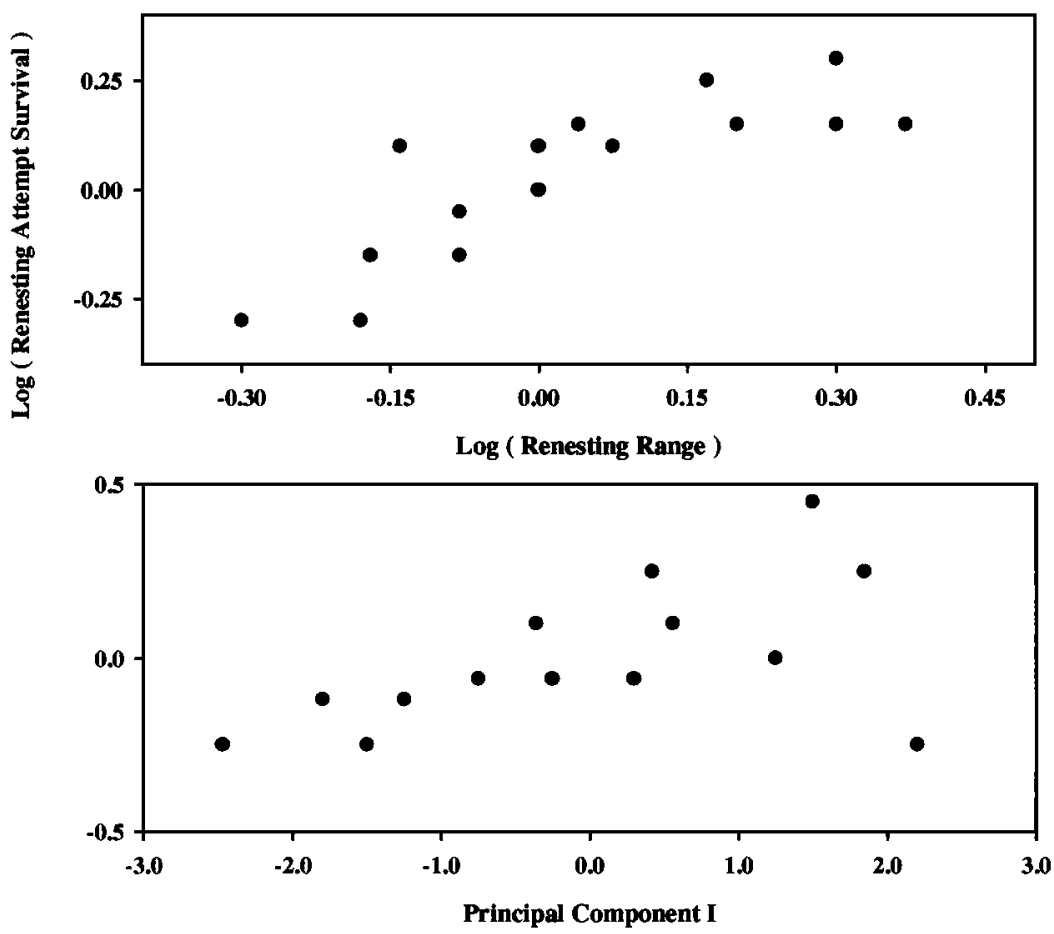

Fig. 6. Partial-regression residual plots illustrating relationship between survival of renesting attempt and amount of overlap between prenesting and renesting ranges, size of renesting range, and PCI (see text for further explanations).

fects, and this variation subsequently affected reproductive performance (Porter et al. 1983). Such variation in physiological condition also may influence the amount of time and energy that can be devoted to habitat sampling. Indeed, our results show that heavier females dispersed farther, had larger clutch sizes, and initiated breeding earlier (Table 3, Fig. 2), all of which suggest that individual variation in physiological condition influences reproductive performance. Greater dispersal by better-quality individuals in turn is correlated with finding high- quality sites early in the season, which further increases the probability of nest survival (Fig. 3). Early nesting by individuals that move farther also could be caused by reduced competition with conspecifics on new areas, but such possibility requires additional study.

Extent of habitat sampling early in the season also influenced reproductive performance by affecting renesting (Table 4, Figs. 4-6). Females whose first nests were depredated shortly after the onset of incubation moved farther than females that incubated for longer periods before 
nest failure (Table 4, Figs. 4-6). Distance between subsequent nest locations was inversely related to the extent of movements early in the season, which may indicate that movement outside of areas already occupied by conspecifics is one of the main functions of spring movements in turkeys.

Nesting habitats change between first-nesting attempts and renesting attempts in Wild Turkeys (Williams and Austin 1988, Badyaev 1995). Vegetation parameters, which were important to survival of renesting attempts (Table 4, Fig. 6), also were correlated with first nest predation probability (Table 2; Badyaev 1995). This indicates that habitat characteristics of first nests together with first nest survival (i.e. prior experience with nest predation) influenced site selection for renesting attempts (Marzluff 1988). Females that searched larger areas for renests and did so outside the locales they had already moved over in searching for their first nests were more successful than other females. Despite the large size of prenesting ranges and the females' apparent familiarity with these territories, females still benefitted from intensive searching in new areas, perhaps at higher risk to their own survival (e.g. Jenkins et al. 1963, Murray 1967). Thus, it is possible that the prenesting area does not provide unoccupied suitable areas for renesting attempts. Two possible explanations are the limited availability of suitable nest habitats in the study area and differential requirements of habitat characteristics for first nests and renests (Badyaev 1995). Observed dispersion patterns of first nests and renests are probably caused by the joint influence of the distribution of suitable nest sites, territorial interactions among nesting females, and prior experience with nest predation (e.g. Marzluff 1988, Andrén 1991, Badyaev and Faust 1996). For example, in Willow Ptarmigan (Lagopus lagopus), renesting sites were located farther from depredated nests than expected had they been placed at random, but the distance between these two nest sites did not influence the probability of predation at the second nest (Schieck and Hannon 1993).

In summary, individual attributes and habitat distribution may influence the ability of individuals to sample habitats and, thus, may affect access to high-quality habitats. Greater habitat sampling by individuals is reflected in higher reproductive success and survival. In addition, in unsuccessful nesting attempts, an experience with predation and energy expenditure for the failed nesting attempt may affect female physiological condition and also determine the subset of habitats to be avoided for renesting. These factors, in turn, could influence habitat sampling and survival of the renesting attempt. Thus, the process of habitat selection may be complex, and ecological determinants of habitat sampling need further study in a wider range of species.

\section{ACKNOWLEDGMENTS}

We thank D. Frick, D. Hasenbeck, A. Hodgson, T. Lane, K. Lynch, A. Mouhalis, and K. Teter for help with the fieldwork. This article was substantially improved by comments from M. L. Cody, E. P. Greene, F. C. James, J. E. Johnson, J. S. Marks, G. D. Schnell, K. G. Smith, J. H. Withgott, and two anonymous reviewers. This study was supported by the Arkansas Game and Fish Commission, the Arkansas State Chapter of the National Wild Turkey Federation, the Arkansas Cooperative Fish and Wildlife Research Unit, and the University of Arkansas.

\section{LITERATURE CITED}

ANDRÉN, H. 1991. Predation: An overrated factor for over-dispersion of birds' nests? Animal Behaviour 41:1063-1069.

BADYAEV, A. V. 1995. Nest habitat selection and nest success of eastern Wild Turkey in the Arkansas Ozark Highlands. Condor 97:221-232.

BADYAeV, A. V., W. J. ETges, AND T. E. MARTIN. 1996 a. Ecological and behavioral correlates of variation in seasonal home ranges of Wild Turkeys. Journal of Wildlife Management 60:154-164.

BadyaeV, A. V., W. J. EtGes, AND T. E. MARTIN. 1996b Age-biased spring dispersal in male Wild Turkeys. Auk 113:240-242.

Badyaev, A. V., AND J. D. Faust. 1996. Nest site fidelity in female Wild Turkeys: Potential causes and reproductive consequences. Condor 98: in press.

BoAG, D. A., K. H. McCourt, P. W. Herzog, and J. H. AlWAY. 1979. Population regulation in Spruce Grouse: A working hypothesis. Canadian Journal of Zoology 57:2275-2284.

BROOKE, M. DE L. 1979. Differences in the quality of territories held by Wheatears (Oenanthe oenanthe). Journal of Animal Ecology 48:21-32.

CODY, M. L. (Ed.). 1985. Habitat selection in birds. Academic Press, New York.

FRETWELL, S. D. 1972. Populations in seasonal environment. Princeton University Press, Princeton, New Jersey.

FrETWELl, S. D., AND H. L. LuCAS, JR. 1970. On territorial behavior and other factors influencing 
habitat distribution in birds. I. Theoretical development. Acta Biotheoretica 19:16-36.

GuSTAFSSON, L. 1989. Life-history trade-offs and optimal clutch size in relation to age in the Collared Flycatcher. Pages 235-246 in Population biology of passerine birds. An integrated approach (J. Blondel, A. Gosler, J.-D. Lebreton, and R. McCleery, Eds.). NATO ASI Series G: Ecological Sciences, vol. 24. Springer-Verlag, Berlin.

HANNON, S. J., L. G. SOPUCK, AND F. C. ZWICKEL. 1982. Spring movements of female Blue Grouse: Evidence for socially induced delayed breeding in yearlings. Auk 99:687-694.

Harvey, P. H., P. J. Greenwood, and M. J. StenNing. 1984. Breeding dispersal of the Pied Flycatcher (Ficedula hypoleuca). Journal of Animal Ecology 53:727-736.

Healy, W. M. 1992. Behavior. Pages 46-65 in The Wild Turkey: Biology and management (J. G. Dickson, Ed.). Stackpole Books, Harrisburg, Pennsylvania.

HeINRICH, B. 1979. "Majoring" and "minoring" by foraging bumblebees, Bombus vagans: An experimental analysis. Ecology 60:245-255.

HewIT, O.H. 1967. The Wild Turkey and its management. The Wildlife Society, Washington, D.C.

HöGSTEDT, G. 1980. Evolution of clutch size in birds: Adaptive variation in relation to territory quality. Science 210:1148-1150.

JACKSON, D. A. 1993. Stopping rules in principal components analysis: A comparison of heuristical and statistical approaches. Ecology 74:22042214.

Jenkins, D., A. Watson, AND G. R. MilleR. 1963. Population studies on Red Grouse, Lagopus lagopus scoticus (Lath.) in north-east Scotland. Journal of Animal Ecology 32:317-376.

JoHNSON, M. L., AND M. S. GAINES. 1990. Evolution of dispersal: Theoretical models and empirical tests using birds and mammals. Annual Reviews of Ecology and Systematics 21:449-480.

KENWARD, R. 1990. Ranges IV. Software for analyzing animal location data. Institute of Terrestrial Ecology, Wareham, United Kindom.

MARTIN, T. E. 1992. Breeding season productivity: What are the appropriate habitat features for management? Pages 455-473 in Ecology and conservation of Neotropical migrant landbirds (J.M. Hagan III and D.W. Johnston, Eds.). Smithsonian Institution Press, Washington, D.C.

MARTIN, T. E. 1993. Nest predation and nest sites: New perspectives on old patterns. BioScience 43 : 523-532.

Marzluff, J. M. 1988. Do Pinyon Jays alter nest placement based on prior experience? Animal Behaviour 36:1-10.

MONTGOMERY, D. C., AND E. A. PECK. 1992. Introduction to linear regression analysis, 2 nd ed. John Wiley and Sons, New York.
MurRay, B. G., JR. 1967. Dispersal in vertebrates. Ecology 48:975-978.

NuDDS, T. D. 1977. Quantifying the vegetative structure of wildlife cover. Wildlife Society Bulletin 5:113-117.

Nugent, D. P., AND D. A. Boag. 1982. Communication among territorial female Spruce Grouse. Canadian Journal of Zoology 60:2624-2632.

ORIANS, G. H., AND J. F. WITTENBEGER. 1991. Spatial and temporal scales in habitat selection. American Naturalist 137:S29-S49.

PARKER, G. A. 1983. Mate quality and mating decisions. Pages 141-166 in Mate choice (P. Bateson, Ed.). Cambridge University Press, Cambridge.

PetTIFor, R. A., C. M. Perrins, ANd R. H. MCCleERY. 1988. Individual optimization of clutch size in Great Tits. Nature 336:360-362.

Porter, W. F., G. C. Nelson, AND K. MAtTson. 1983. Effects of winter conditions on reproduction in northern Wild Turkey population. Journal of Wildlife Management 47:281-290.

Pulliam, R. H., AND B. J. Danielson. 1991. Sources, sinks, and habitat selection: A landscape perspective on population dynamics. American Naturalist 137:S50-S66.

REAL, L. 1990. Search theory and mate choice. I. Models of single-sex discrimination. American Naturalist 136:376-404.

SAS INSTITUTE. 1989. SAS/STAT user's guide, version 6. Cary, North Carolina.

SCHIECK, J. O., AND S. J. HanNon. 1993. Clutch predation, cover, and the overdispersion of nests of the Willow Ptarmigan. Ecology 74:743-750.

SchmuTZ, J. A., AND C. E. BRAUN. 1989. Reproductive performance of Rio Grande Wild Turkeys. Condor 91: 675-680.

SChMutz, J. A., C. E. BRAUN, AND W. F. ANDELT. 1989. Nesting habitat use of Rio Grande Wild Turkeys. Wilson Bulletin 101:591-598.

SMITH, W. P., E. P. LAMberT, AND R. D. TeITElbaum. 1989. Seasonal movement and home range differences among age and sex groups of eastern Wild Turkey within southeastern Louisiana. Proceedings of the International Biotelemetry Conference 10:151-158.

Stephens, D. W., AND J. R. KREBS. 1986. Foraging theory. Princeton University Press, Princeton, New Jersey.

Williams, L. E., JR., AND D. H. Austin. 1988. The Wild Turkey in Florida. Technical Bulletin 10. University of Florida Press, Gainesville.

WHITHAM, T. G. 1980. The theory of habitat selection: Examined and extended using Pemphigus aphids. American Naturalist 115:449-466

ZAR, J.H. 1984. Biostatistical analysis. Prentice-Hall, Englewood Cliffs, New Jersey.

ZWICKEL, F. C. 1980. Surplus yearlings and the regulation of breeding density in Blue Grouse. Canadian Journal of Zoology 58:896-905. 